\title{
44. ON THE UTILITY OF CHEMICAL DATA FOR THE DETECTION OF VERTICAL PORE-WATER MOVEMENT IN MARINE SEDIMENTS ${ }^{1}$
}

\author{
T. R. S. Wilson, Institute of Oceanographic Sciences, Wormley, Godalming, Surrey, United Kingdom \\ and \\ D. L. Miles, British Geological Survey, Hydrogeological Unit, Crowmarsh Gifford, \\ Wallingford, Oxfordshire, United Kingdom ${ }^{2}$
}

\begin{abstract}
The suggestion that nuclear waste material might be buried within the sediments of the deep ocean has increased interest in possible ways that vertical pore-water movement might be detected and measured. A heat-flow station (Discovery 10335) previously occupied near Kings Trough indicated nonlinear temperature-depth profiles in the surficial sediments, which could be interpreted in terms of a very high upward pore-water velocity. The calcium and magnesium pore-water profiles at Site 608 , however, prove to be unusually linear and show a strong inverse correlation with each other. In these circumstances it is very unlikely that vertical pore-water movements have occurred, and the application of a simple model indicates that, given the assumptions of this model, the vertical pore-water advection velocity has been zero $\pm 0.006 \mathrm{~cm} \mathrm{yr}^{-1}$ for a substantial fraction of the recent sedimentological history of this area.
\end{abstract}

\section{INTRODUCTION}

The thermal characteristics of the deep ocean floor have been shown to approximate those of a conductively cooling lithospheric slab (Parsons and Sclater, 1977), a model which appears valid except in areas close to active spreading centers. In those areas, it is generally accepted that heat is actively transported by convective cells, in a process involving the circulation of solutions derived ultimately from seawater. Over the major areas of the ocean basins, however, gross thermal considerations do not indicate that convective heat transport is active.

In spite of this, several studies of the detailed distribution of heat flow have revealed temperature distributions interpreted as evidence of convective flow in sedimentary basins distant from spreading centers (Anderson et al., 1979; Langseth and Herman, 1981; Burgess and Judge, 1981). In general, models of geochemical processes in the deep ocean do not consider the possibility of bulk pore-water flow, other than that attributable to compaction. Crowe and McDuff (1979) have made a direct comparison of chemical and thermal data obtained at an equatorial Pacific site, and concluded that the maximum advective velocities consistent with the chemical data were always at least two orders of magnitude less than those implied by the thermal data. Noel (1984) has provided a valuable review of possible alternative explanations for the nonlinearities in the thermal profile.

In principle, study of the concentration profiles of chemical species within sediments would reveal the existence of any advective component of transport. Unfor-

\footnotetext{
1 Ruddiman, W. G., Kidd, R. B., Thomas, E., et al., Init. Repts. DSDP, 94: Washington (U.S. Govt. Printing Office).

Addresses: (Wilson) Institute of Oceanographic Sciences, Brook Road, Wormley, Godalming, Surrey GU8 SUB, United Kingdom; (Miles) British Geological Survey, Hydrogeological Unit, Maclean Building, Crowmarsh Gifford, Wallingford, Oxfordshire OX10 8BB, United Kingdom.
}

tunately, the steepest gradients usually occur near the sediment/water interface. Many other processes are active in this region, and not all are at present well characterized. The uncertainties associated with such processes as compaction, bioturbation, and diagenetic reaction are such that the advective signal is difficult to discern with confidence. Deeper within the sediment, however, a more simple situation may exist, and it has been suggested (Gieskes, personal communication, 1983) that the advective signal, if any, should be easily detectable in the chemical profiles. Site 608 is of particular interest from this point of view because the calcium and magnesium profiles are unusually well correlated. Since the site lies in a region of the Atlantic which has been suggested as a possible general area for studies on the burial of nuclear waste, the detection of any natural advection is also of some practical interest. Kidd et al. (1983) report a highly nonlinear temperature-depth gradient for one of three measurements at a station occupied $60 \mathrm{n}$. mi. southeast of Site 608 (Discovery station 10335). They discuss several possible causes for this observation, including topographic effects and possible vertical water movement. Assuming the latter explanation, a fit of the data to the diffusion-advection model of Mansure and Reiter (1979) gave an upward velocity estimate of $52 \mathrm{~cm} \mathrm{yr}^{-1}$.

McDuff and Gieskes (1979) and McDuff (1981) reported that many DSDP sites show increases in pore-water calcium ion concentration with depth, correlated linearly with a decrease in magnesium concentration with depth. They conclude that these distributions result primarily from physical transport processes, chemical reaction being confined to a depth zone at or near the sediment basalt interface. Data presented here for analyses of pore-water subsamples from Site 608 are interpreted in the context of this model. Using this approach, it is possible to estimate an upper limit to possible steadystate advection velocities at Site 608 . 


\section{METHOD}

Pore waters were sampled on board ship by pressure-squeezing of core sections, using the standard DSDP procedures and equipment. Subsamples $(100 \mu)$ were diluted to $5 \mathrm{ml}$ with dilute hydrochloric acid (1 $\mathrm{ml}$ Analar $\mathrm{HCl}$ to $100 \mathrm{ml}$ double-distilled water) and analyzed, inter alia, for calcium and magnesium by inductively coupled plasma emission spectrometry using an Applied Research Laboratories 34000C system. Multi-element standard solutions (prepared from appropriate Analar or specpure-grade reagents and acidified to 1 vol. \% with Aristar $\mathrm{HCl}$ ) were employed for initial calibration. Selected standards were also reanalyzed at intervals to monitor any slight instrumental drift. A suitably diluted sample of International Standard Seawater was also analyzed periodically as a further quality control check. The results are presented in Table 1.

\section{DISCUSSION}

The calcium and magnesium data of Figure 1 exhibit a classic linear correlation of the type frequently reported from DSDP sites (McDuff and Gieskes, 1976; McDuff, 1981, and references therein). McDuff and Gieskes interpret their results in terms of a reaction zone at and below basement depth where magnesium is consumed and calcium liberated. A linear least-squares fit to the data gives a positive slope of $0.0194 \times 10^{-8} \mathrm{~mol} \mathrm{~cm}^{-4}$ for calcium and negative slope of $0.0219 \times 10^{-8} \mathrm{~mol}$ $\mathrm{cm}^{-4}$ for magnesium. Since the free-solution diffusion coefficients at $0^{\circ} \mathrm{C}$ for those ions are $3.73 \times 10^{-6} \mathrm{~cm}^{2} \mathrm{~s}$ and $3.56 \times 10^{-6} \mathrm{~cm}^{2} \mathrm{~s}$, respectively ( $\mathrm{Li}$ and Gregory, 1974), a simple steady-state Fickian diffusion model treatment gives a flux ratio (flux $\mathrm{Ca} /$ flux $\mathrm{Mg}$ ) of 0.93 . McDuff (1981) summarizes data from 23 DSDP sites showing linearly correlated calcium and magnesium gradients. The relatively low $\mathrm{Ca} / \mathrm{Mg}$ ratio found here is close to what would be predicted from the calcium gradient data on the basis of the empirical relationship between these parameters noted by McDuff.

To evaluate the extent to which these data constrain the maximum advective velocity, it is necessary to decide what degree of deviation from the linear diffusion profile could be detected unequivocally. The criterion adopted here is that the true profile would need to differ systematically from the line of Figure 1 at its midpoint by a maximum amount of 3 times the calculated standard error of the data.

Table 1. Analyses $(\mathrm{mmol} / \mathrm{l})$ of porewater from Site 608.

\begin{tabular}{ccc}
\hline $\begin{array}{c}\text { Sub-bottom } \\
\text { depth } \\
(\mathrm{m})\end{array}$ & Calcium & Magnesium \\
\hline 7 & 10.2 & 53.3 \\
36 & 10.8 & 52.5 \\
84 & 11.7 & 50.6 \\
123 & 12.3 & 50.0 \\
180 & 12.8 & 51.0 \\
210 & 13.7 & 48.5 \\
230 & 13.2 & 48.5 \\
248 & 13.3 & 47.7 \\
267 & 13.5 & 47.9 \\
286 & 14.7 & 48.3 \\
324 & 15.3 & 46.3 \\
344 & 16.2 & 45.3 \\
363 & 16.6 & 45.7 \\
372 & 16.5 & 46.5 \\
401 & 18.3 & 44.0 \\
\hline
\end{tabular}

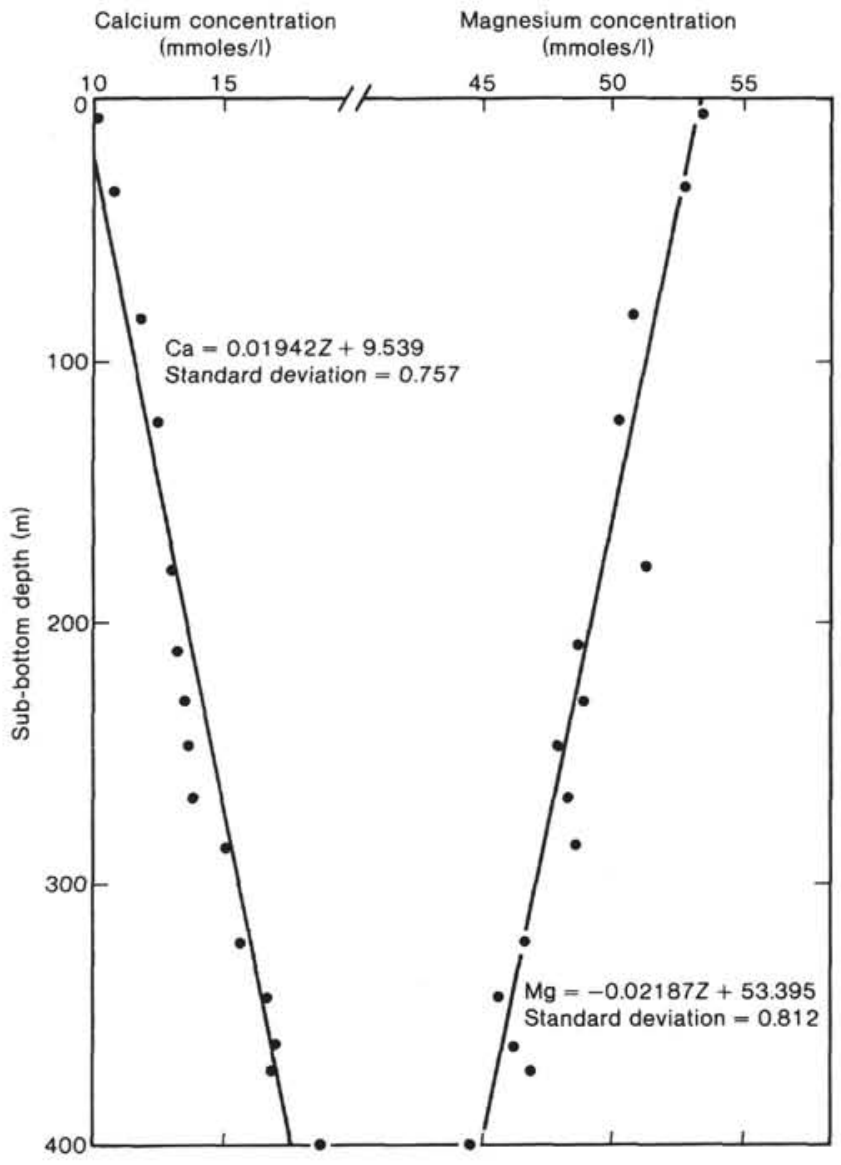

Figure 1. Site 608 pore-water profiles. Lines shown for calcium and magnesium are least-squares fit to the data; $Z$ represents depth.

To determine what maximum advection rate is implied by this constraint, two possible approaches are available. One, adopted by Cranston (1983), involves the derivation of an expression for the concentration in terms of, inter alia, the advection velocity. This may then be evaluated for various velocities to select one which matches the required profile. Alternatively, an expression for the velocity necessary to cause an observed deviation from linearity can be derived, so that the required velocity may be calculated directly. In the following treatment, the necessary expression for the second approach is obtained, and it is shown that the two approaches yield results which are in very close agreement.

The diagenetic equation, for the case where only diffusion and advection control the concentration $C$ at depth, is

$$
-D \frac{d^{2} C}{-d Z^{2}}+\frac{V d C}{d z}=0
$$

Setting $V / D=\alpha$, the solution is given by

$$
C_{z}=A e^{\alpha z}+B
$$

which, with boundary conditions $C=C_{0}$ at $Z=0$ and $C=C_{1}$ at $Z=H$ 
gives

$$
C_{z}=\frac{\left[\left(C_{0}-C_{1}\right) e^{\alpha z}+C_{1}-C_{0} e^{\alpha H}\right]}{1-e^{\alpha H}}
$$

Let

$$
G_{z}=\frac{C_{z}-C_{1}}{C_{0}-C_{1}}
$$

it follows that

$$
G_{z}=\frac{e^{\alpha z}-e^{\alpha H}}{1-\mathrm{e}^{\alpha H}}
$$

In general, it does not appear possible to transform Equation 5 to give an expression for $\alpha$. If, however, we consider the midpoint of the profile, we may define a quantity $\delta$ which represents the fractional deviation of the concentration profile from a linear relationship. Then,

$G_{H / 2}=\frac{1 / 2\left(C_{0}-C_{1}\right)+\Delta}{C_{0}-C_{1}}$ and $\delta=\frac{2 \Delta}{\left(C_{0}-C_{1}\right)}$

where $\Delta$ represents the deviation from linearity at the midpoint, caused by advection. It follows that

$$
G_{H / 2}=1 / 2(1+\delta)
$$

and thus,

$$
\frac{1+\delta}{2}=\frac{e^{\alpha H / 2}-\left(e^{\alpha H / 2}\right)^{2}}{1-\left(e^{\alpha H / 2}\right)^{2}}
$$

which has the solution

$$
e^{\alpha H / 2}=\frac{1+\delta}{1-\delta}
$$

so that

$$
\alpha H=2 \ln \left[\frac{1+\delta}{1-\delta}\right]
$$

Back-substituting for $\delta$ in terms of measured quantities, the advective velocity $V$ is given by

$$
V=\frac{D}{H} 2 \ln \left(\frac{C_{0}-C_{1}+2 \Delta}{C_{0}-C_{1}-2 \Delta}\right)
$$

The concentration values necessary to evaluate this expression are shown in Figure 1. Strictly speaking, the treatment is valid only for constant diffusion coefficient; fortunately, the two major factors affecting diffusion coefficients in sediment columns, tortuosity and temperature, tend to oppose each other in effect. For tortuosity the relevant relation is $D_{s}=D / \phi F$, where $D_{s}$ is the diffusion coefficient valid for diffusion in pore water, $D$ is the free-solution diffusion coefficient, $\phi$ is the porosity, and $F$ the formation factor. This last may be approximated by the Archie's law relationship $F=\phi^{-2}$, to obtain an empirical relationship for the tortuosity effect (Berner, 1980).

The effect of the geothermal gradient is to increase values of the sediment diffusion coefficient with depth. An estimate of this effect may be derived; to do so it has been assumed that the geothermal gradient is $0.04^{\circ} \mathrm{C}$ $\mathrm{m}^{-1}$ and that the variation of diffusion coefficient may be approximated by a temperature coefficient of $0.17 \times$ $10^{-6} \mathrm{~cm}^{2} \mathrm{~s}^{-1}{ }^{\circ} \mathrm{C}^{-1}$ for calcium and $0.14 \times 10^{-6} \mathrm{~cm}^{2} \mathrm{~s}^{-}$ $1{ }^{\circ} \mathrm{C}^{-1}$ for magnesium (Li and Gregory, 1974). Site-data porosity values were used. On this basis it is estimated that the diffusion coefficient $\left(D_{s}\right)$ for calcium ranges between a minimum $2.4 \times 10^{-6} \mathrm{~cm}^{2} \mathrm{~s}^{-1}$ at $50 \mathrm{~m}$ and a maximum of $3.4 \times 10^{-6} \mathrm{~cm}^{2} \mathrm{~s}^{-1}$ at $400 \mathrm{~m}$, the bottom of the section considered. Corresponding values for magnesium are $2.5 \times 10^{-6} \mathrm{~cm}^{2} \mathrm{~s}^{-1}$ and $3.1 \times 10^{-6} \mathrm{~cm}^{2} \mathrm{~s}^{-1}$. In the discussion given here, a constant value of $2.8 \times$ $10^{-6} \mathrm{~cm}^{2} \mathrm{~s}^{-1}$ has been assumed for both calcium and magnesium; for reasons to be discussed shortly, the final conclusions are not strongly influenced by small variations in this parameter.

Values for the advective velocity corresponding to the minimum detectable deviation from linearity ( 3 times the observed standard error of the data) were calculated using Equation 11. The value found for calcium was 5.89 cm kyr. ${ }^{-1}$ and for magnesium $5.52 \mathrm{~cm} \mathrm{kyr.}{ }^{-1}$. These values are very small, and illustrate the sensitivity of diffusion profiles to advective processes.

As a cross check on the applicability of Equation 11, a numerical evaluation based on Equation 3 was made. The value of $C$ corresponding to a given value of $V$ was calculated for slowly increasing values of $V$ until the criterion value of 3 times the standard error of the data was exceeded. The minimum detectable advection rate calculated in this way was $5.9 \mathrm{~cm} \mathrm{Kyr} .^{-1}$ for the calcium data and $5.5 \mathrm{~cm} \mathrm{kyr.}{ }^{-1}$ for the magnesium data. It will be seen that these results are in excellent agreement with those calculated using Equation 11. The deviation due to advection is symmetrical for change in sign of the advective velocity, so that the results may be summarized by the statement that the calcium and magnesium profiles are consistent with zero advection $\pm 0.006 \mathrm{~cm}$ yr. ${ }^{-1}$, if the assumptions are valid. Thus, it will be seen that the data presented constrain the possible velocity of advection to a very small range on either side of zero.

It is interesting to consider the effect of compaction relative to this conclusion. At steady state, movement of pore water relative to the solid phase as a result of compaction is significant only when the porosity gradient $d \phi / d z$ differs from zero. For the present case, the rate of advection due to compaction is given by Berner (1980) as

$$
V=\phi_{\mathrm{z}} \omega_{\mathrm{z}} / \phi
$$

where $\phi$ is the porosity and $\omega$ is the rate of burial of solid phase relative to the sediment/water interface. The subscript $z$ refers to the asymptotic values of $\phi$ (and 
thus $\omega$ ) reached with increasing depth. At Site 608, shipboard site data show $\phi$ falling from a value near 0.7 close to the sediment surface to an asymptotic value of about 0.57 below $100 \mathrm{~m}$ sub-bottom. Accumulation rates from Institute of Oceanographic Sciences (IOS) cores recovered in the area averaged $2.6 \mathrm{~cm} \mathrm{kyr.}{ }^{-1}$, whereas site data reported for Hole 608 indicate an accumulation rate of $2.9 \mathrm{~cm} \mathrm{kyr.}^{-1}$. Assuming an $\omega_{0}$ of $2.9 \mathrm{~cm} \mathrm{kyr}^{-1}$, this implies an $\omega_{z}$ value of about $2.1 \mathrm{~cm} \mathrm{kyr.}{ }^{-1}$ at this site. It follows that advection, relative to the solid phase, due to compaction, equals $1.3 \mathrm{~cm} \mathrm{kyr}^{-1}$ at the sediment/water interface and is close to zero at and below $50 \mathrm{~m}$ sub-bottom. At depths greater than $50 \mathrm{~m}$, this process can produce negligible distortion of the calcium and magnesium profiles. It should be emphasized that this does not imply upward movement relative to the sediment/water interface, since both solid and solution phases are moving downward relative to this datum.

\section{CONCLUSIONS}

The assumptions on which the foregoing conclusions are based are of course somewhat simplistic. In particular, the assumption of zero net reaction of calcium and magnesium within the sediment layer (the justifications for which are summarized by McDuff, 1981), and the assumption of constant diffusion coefficient with depth, are open to criticism. It is arguable, for instance, that the curvature of a profile caused by advection may be exactly canceled by an equal or opposite curvature caused by reaction with the solid phase. In the present case, however, the diffusive fluxes are in opposite senses. Consequently, it is necessary to postulate that such a reaction mechanism must have an equal influence on both the calcium and magnesium profiles, capable of maintaining a linear profile for both. Since an upward flow would produce excess calcium and magnesium at middepth, relative to the linear diffusive case, whereas a downward flow would produce a deficit, such a reaction would have to produce or remove both of these ions in similar quantities. This rules out simple $\mathrm{Ca} / \mathrm{Mg}$ exchange equilibria and, although, it is possible to imagine other reaction processes which could act so as to mask advection, the quantities of material involved over time, and the balance of fortuitously determined processes which must be postulated, make them less likely.

A systematic variation in diffusion coefficient, due to some factor not considered in the preceding discussion, could affect the slopes of both calcium and magnesium profiles in such a way as to cancel an advective nonlinearity. At constant flux, the slope of the concentration profile varies inversely with change in diffusion coefficient. The high sensitivity of the slope of the concentration profile to advection means that very large changes in $D_{s}$ would be needed to cancel the effects of quite modest advective velocities; in the present case, the slope changes by a factor of 2 for an advection rate change from 0 to $10 \mathrm{~cm} \mathrm{kyr.}{ }^{-1}$, and by an order of magnitude for a change from 0 to $22 \mathrm{~cm} \mathrm{kyr.}^{-1}$. Thus, although the effects of very small advection rates might be concealed by variation in $D_{s}$, this mechanism is not capable of compensating for larger advective fluxes.
It appears from this that the dominant influence on the calcium and magnesium profiles at Site 608 is diffusional transport through the sediment column. This conclusion would not be seriously changed by likely errors in the assumed diffusion coefficient. It is possible that reactions within the sediment column are, fortuitously, just of such a nature and direction as to mask a larger advective signal; this would, however, be a rather unlikely concatenation of circumstances. We therefore concluded that the advective flux at Site 608 is $0 \pm 0.006 \mathrm{~cm} \mathrm{yr}^{-1}$. The data presented here are incompatable with large advection rates. It seems likely, then, that the nonlinear temperature profile reported by Kidd et al., (1983) was not caused by pore-water movement but by one of the alternative mechanisms discussed by Noel (1984).

\section{ACKNOWLEDGMENTS}

The authors acknowledge their indebtedness to David Webb for mathematical advice and to the shipboard party of Leg 94; especially to Jim Pine for obtaining the samples. We thank reviewers J. M. Gieskes, R. Cranston, and B. Boudreau for their helpful contributions to the final form of the paper.

Part of this research was supported by a contract with the U.K. Department of the Environment, as part of its radioactive waste management research program. The results will be used in the formulation of government policy, but at this stage they do not necessarily represent government policy.

\section{REFERENCES}

Anderson, R. N., Hobart, M. A., and Langseth, M. G., 1979. Geothermal convection through oceanic crust and sediments in the Indian Ocean. Science, 204:828-832.

Berner, R. A., 1980. Early Diagenesis: A Theoretical Approach: Princeton, N.J. (Princeton University Press).

Burgess, M., and Judge, A., 1981 Heat-flow studies in the Sohm Abyssal Plain and their relevance to nuclear waste disposal investigations. Report to the Division of Seismology and Geothermal Studies, Energy Mines and Resources. 81-15. Ottawa, Canada.

Cranston, R. E., 1983. Report to the eighth annual meeting of the NEA/Seabed Working Group, Varese. Sandia Report SAND832122. Albuquerque, New Mexico.

Crowe, J., and McDuff, R. E., 1979. Temperature and porewater chemistry. Profiles of sediments in the equatorial Pacific. Incompatible results? Trans. A. Geophys. Un., 60:863. (Abstract)

Kidd, R. B., Searle, R. C., Weaver, P. P. E., Jacobs, C. L., Huggett, Q. J., et al., 1983. King's Trough Flank: Geological and Geophysical Investigations of Its Suitability for High-Level Radioactive Waste Disposal. Inst. Oceanogr. Sci. Rept., 166.

Langseth, M. G., and Herman, B. M., 1981. Heat transfer in the oceanic crust of the Brazil Basin. J. Geophys. Res., 86:10905-10819.

Li, Y., and Gregory, S., 1974. Diffusion of ions in seawater and in deep sea sediments. Geochim. Cosmochim. Acta, 38:703-714.

McDuff, R. E., 1981. Major cation gradients in DSDP interstitial waters; The role of diffusive exchange between seawater and the upper oceanic crust. Geochim. Cosmochim. Acta, 45:1703-1705.

McDuff, R. E. and Gieskes, J. M., 1976. Calcium and magnesium profiles in DSDP interstitial waters: Diffusion reaction. Earth Planet. Sci. Lett., 33:1-10.

Mansure, A. J., and Reiter, M., 1979. A vertical groundwater movement correction for heat flow. J. Geophys. Res., 84:3490-3496.

Noel, M., 1984. Origins and significance of non-linear temperature profiles in deep-sea sediments. Geophys. J. R. Astron. Soc., 76: 673-690.

Parsons, B., and Sclater, J. G., 1977. An analysis of the variation of ocean floor bathymetry and heat flow with age. J. Geophys. Res., 82:803-827.

Date of Initial Receipt: 5 November 1984

Date of Acceptance: 29 May 1985 